\title{
Original
}

\section{The Effect of Additive Formula Diet on Bone Structure of the Femur in Ovariectomized Rats}

\author{
Kanami Sato'), Takahiro Takahashi'), Hiroshi Nakada ${ }^{2,4)}$, Toshiro Sakae ${ }^{3)}$, Takehiro Watanabe ${ }^{2,4)}$, Hiroki Sato', \\ Daisuke Isaji ${ }^{1)}$, Atsuko Gunjii, and Yasuhiko Kawai ${ }^{2,4)}$ \\ 1) Nihon University Graduate School of Dentistry at Matsudo, Chiba, Japan \\ 2) Department of Removable Prosthodontics, Nihon University School of Dentistry at Matsudo, Chiba, Japan \\ 3) Department of Histology, Nihon University School of Dentistry at Matsudo, Chiba, Japan \\ 4) Research Institute of Oral Science, Nihon University School of Dentistry at Matsudo, Chiba, Japan \\ (Accepted for publication, December 22, 2016)
}

\begin{abstract}
Osteoporosis is a major problem in the elderly population worldwide. Low calcium intake and vitamin D blood level are risk factors for osteoporosis, and improving their intake is effective in patients with micronutrients deficiency. However, the effect of these interventions is ambiguous. Additive formula diet (AFD) contains fructo-oligosaccharide (FOS), isoflavone (ISO) and $1.0 \%$ citric acid $\mathrm{Ca}$ as a supplement for patients with osteoporosis. We aimed to investigate the effect of AFD on bone structure of the femur in ovariectomized rats. Sixteen 20 -week old ovariectomized rats were randomly distributed into 2 groups; one group was fed normal diet $(\mathrm{N}, \mathrm{n}=8)$ and the second group was fed AFD $(\mathrm{A}, \mathrm{n}=8)$. Both groups were fed for 24 weeks, and body weight was measured at 8 and 24 weeks. After measuring the weight at 24 weeks, rats were euthanized using carbon dioxide. Lateral femur bone was extracted, and bone mineral density (BMD) and bone mineral content (BMC) were measured via micro computed tomography. Non-decalcified ground sections of the femur were examined via polarized-light microscopy. At 24 weeks, BMD and BMC were significantly higher for the A group than in the $\mathrm{N}$ group. The A group showed significantly better structural values with respect to Tb.Th, Tb.N, Tb.sp, Tb.spac and SMI than the N group. The A group showed significantly denser trabecular observations than the $\mathrm{N}$ group. Examination of the non-decalcified ground section from the A group showed strong polarized light properties of orange compared with sections from the $\mathrm{N}$ group. AFD may improve bone turnover in osteoporosis with the expectant decrease in the incidence of falls and bone fractures, which may enhance the quality of life of the elderly.
\end{abstract}

Key words: Additive formula diet, Osteoporosis, Menopause, ovariectomy, femur

\section{Introduction}

The world's aging population is showing a marked increase from $5.1 \%$ in 1950 to $7.7 \%$ in $2010^{1)}$. This rapid increase is still in progress, and expected to lead to a "super-aging society". The increase in Japan's aging population can be observed when comparing it to other industrialized countries; up until the 1980s this population was not prominent, then it started to increase in the 1990s, and reached its highest level in $2005^{1}$. Consequently, an increase in diseases specific to geriatrics is expected. Bone and joint diseases are common among the Asian population, with their prevalence tripling over the past 20 years, and with $80 \%$ of patients being menopausal women. In Japan, although there are

Correspondence to: Dr. Kanami Sato, Nihon University Graduate School of Dentistry at Matsudo, Matsudo, 2-870-1 Sakaecho-nishi, Chiba, 2718587 Japan; Tel: 81-47-360-9378; Fax: 81-47-360-9376; Email: kanami.sato.fujita@gmail.com many patients with osteoporosis, it was speculated that $80 \%$ of them did not receive the required medical care. Osteoporosis increases the risk of bone fractures in the elderly, and consequently, the need for nursing care. Moreover, the anticipated fear of falling limits movement with decreased exercise and bone density. This creates a vicious circle of reduced motor function and further decline of muscle strength. Sarcopenia, defined as the decline in muscle strength, results in decreased daily activity. A previous report showed that sarcopenia and bone volume are strongly correlated $^{2,3)}$

Low calcium intake and vitamin D level in blood were considered as risk factors for osteoporosis, and improving their intake is considered effective, especially for the elderly with micronutrient deficiency due to inadequate drug intake secondary to chronic disease ${ }^{4}$. However, the effect of these interventions is ambiguous $^{5-7)}$. Aiming at efficient intake and absorption of calcium, 
Table 1. Compositions of the diets used

The bait coordinated AIN-93M for the cause. NMD coordinated calcium concentrations by calcium carbonate in $1 \%$ and adjusted phosphorus concentrations to $0.6 \%$. And AFD assumed calcium concentrations $1.0 \%$ by calcium citrate and did phosphorus concentrations with $0.6 \%$. Furthermore, we mixed ISO and FOS with AFD.

\begin{tabular}{|c|c|c|}
\hline Composition & NMD & AFD \\
\hline$\alpha$-Cornstarch & 42.87 & 31.37 \\
\hline$\beta$-Cornstarch & 15.50 & 15.50 \\
\hline Casein & 14.00 & 14.00 \\
\hline L-Cystine & 0.18 & 0.18 \\
\hline \multicolumn{3}{|l|}{ Dextrin } \\
\hline Sucrose & 10.00 & 10.00 \\
\hline Soybean Oil & 4.00 & 4.00 \\
\hline Cellulose Powder & 5.00 & 5.00 \\
\hline Mineral Mixture & 3.50 & 3.50 \\
\hline Vitamin Mixture & 1.00 & 1.00 \\
\hline Choline Bitartrate & 0.25 & 0.25 \\
\hline Tert-Butylhydroquinone & 0.00 & 0.00 \\
\hline \multicolumn{3}{|l|}{ Additives } \\
\hline Calcium carbonate & 0.90 & \\
\hline Fructooligosaccharides & & 10.00 \\
\hline Isoflavone & & 0.50 \\
\hline Calcium citrate tetrahydrate & & 3.00 \\
\hline Calcium phosphate, Dibasic & 2.80 & 1.70 \\
\hline Total $\%$ & 100.00 & 100.00 \\
\hline$C a$ & 1.01 & 1.03 \\
\hline $\boldsymbol{P}$ & 0.60 & 0.61 \\
\hline
\end{tabular}

Table 2. Body weight at different time points 8 weeks, 20 weeks, indicating the average value of the body weight at 48 weeks of age.

\begin{tabular}{|c|c|c|c|}
\hline & 20 weeks old & 8 old weeks after & 24 weeks after \\
\hline OVX+Normal & $202.2 \pm 4.9$ & $284.7 \pm 15.4$ & $341.5 \pm 16.7$ \\
\hline $\mathrm{OVX}+\mathrm{AFD}$ & $202.5 \pm 7.7$ & $233.8 \pm 7.7$ & $267.7 \pm 9.3$ \\
\hline
\end{tabular}

Table 3. Micro-CT of BMD and BMC showing the average value of the $\mathrm{BMD}$ and $\mathrm{BMC}$ in cancellous bone.

\begin{tabular}{|c|c|c|}
\hline & \multicolumn{2}{|c|}{ Trabecular Bone } \\
\hline & BMD & $\mathrm{BMC}$ \\
\hline OVX+Normal & $735.2 \pm 7.5$ & $0.17 \pm 0.07$ \\
\hline $\mathrm{OVX}+\mathrm{AFD}$ & $768.1 \pm 11.2\rfloor$ & $0.67 \pm 0.13$ \\
\hline
\end{tabular}

Nakada et $\mathrm{al}^{8,9)}$ fed ovariectomized osteoporosis-model rats a supplement composed of fructo-oligosaccharide (FOS), isoflavone (ISO) and phosphate $\mathrm{Ca}(3.0 \%$ content), and found a significant effect on bone formation and strength, and quality of the femoral shaft. However, a Ca concentration of $3.0 \%$ is high, and may cause nutritional imbalance due to overdose ${ }^{8)}$.

Therefore, additive formula diet (AFD) was prepared as $1.0 \%$ citric acid $\mathrm{Ca}$ instead of $3 \%$, and was fed to osteoporotic rats with low serum calcium. The results showed that AFD was safe and that it improved metabolism ${ }^{10}$. However, its effect on menopausal osteoporosis is still unknown. Therefore, the aim of this study was to investigate the effect of AFD on bone structure of the femur in ovariectomized rats.

\section{Materials and Methods}

\section{Animals}

Sixteen female Wistar rats (Sankyo Labo Service Co., Tokyo, Japan), aged 20 weeks, were used. They were housed in individual metal cages at a room temperature of $23 \pm 1^{\circ} \mathrm{C}$ and humidity of 50 $\pm 1 \%$, with ad libitum access to food and water. The experimental protocol was approved by an animals' experiment Ethics Committee (approval no. AP13-MD013). All experiments were conducted according to the Guidelines for the Treatment of Animals, Nihon University, Chiba Japan.

\section{Preparation of rats}

The 16 rats were randomly distributed into 2 groups; the $\mathrm{N}$ group $(n=8)$ was fed normal mineral diet (NMD, Oriental Yeast Co., Tokyo, Japan), and the A group $(\mathrm{n}=8)$ was fed AFD (Oriental Yeast Co., Tokyo, Japan). The composition of both formulations was shown in Table 1.

For ovariectomy, the rats were anaesthetized with isoflurane. The abdominal area was sterilized with $75 \%$ ethanol and was surgically opened. Both ovaries were elevated and completely excised, thus completing ovariectomy. Then, the uterus and adipose tissue were placed back into the abdomen, and the incision was sutured. Both groups of rats were on the prescribed the diet at the age of 20 weeks.

\section{Measurement of body weight}

Body weight of all rats was measured at the following times: at intervention initiation, intervention eight weeks later (28 weeks of age time) and intervention 24 weeks later (44 weeks of age time)

\section{Micro-computed tomography (CT) Micro-CT settings}

Micro-CT of the femur was captured by the R_mCT $2^{\circledR}$ (Rigaku Co., Tokyo, Japan). The $\mathrm{R} \_\mathrm{mCT} 2^{\circledR}$ imaging conditions were as follows: tube current $160 \mathrm{iA}$, tube voltage $90 \mathrm{kV}$, FOV $10 \mathrm{~mm}$, 


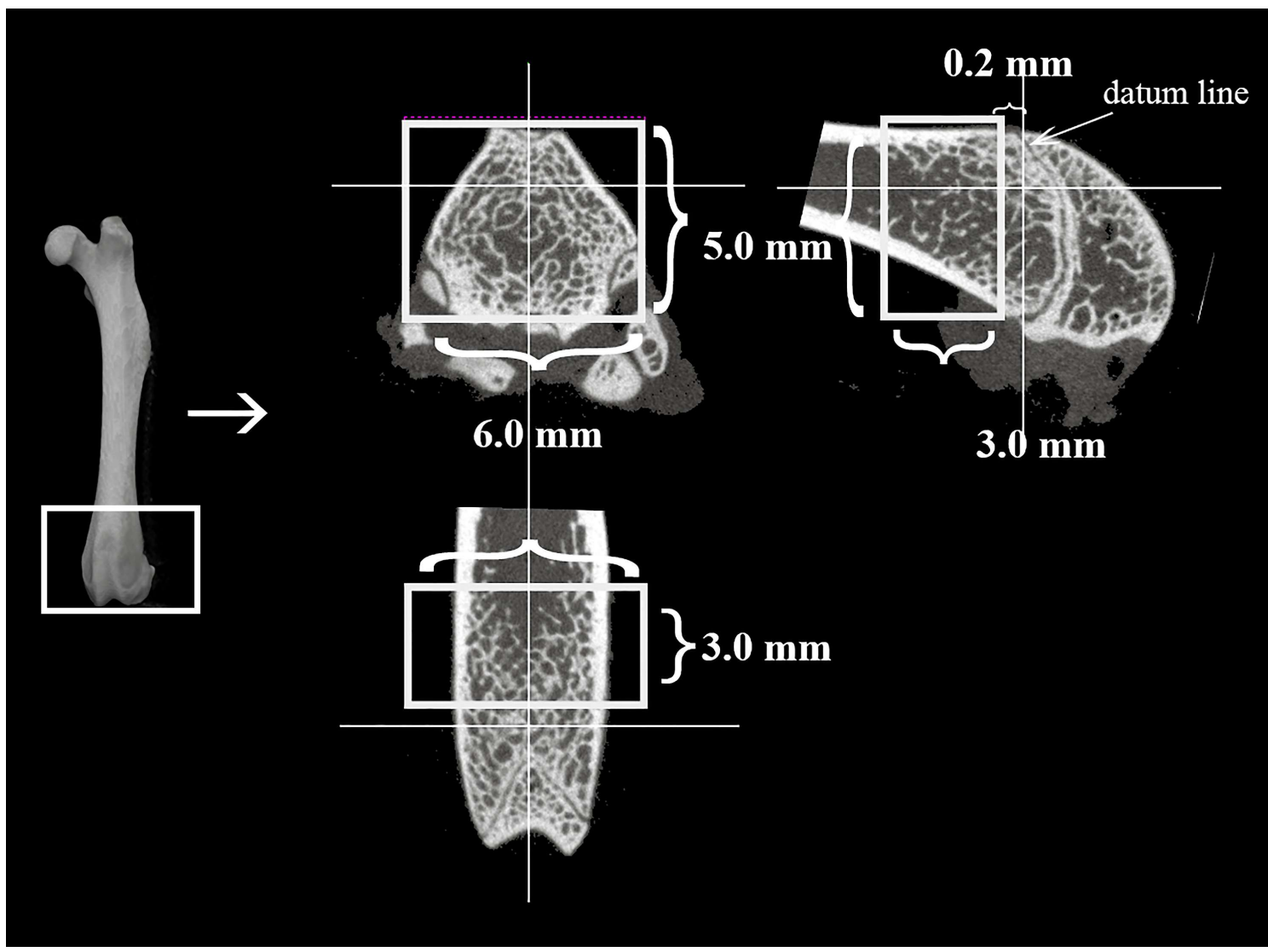

Figure 1. Micro-computed tomography (CT) setting

The figure shows the site of micro-CT imaging. Images are taken for the distal $5.0 \times 6.0 \times 3.0 \mathrm{~mm}$ of the femur.

shooting time 26 seconds, and voxel size $20 \mu \mathrm{m} \times 20 \mu \mathrm{m} \times 20$ $\mu \mathrm{m}$. Micro-CT images were taken for the femur, and phantoms for CT-value proofreading were taken after 24 weeks. Imaging was on the distal femoral metaphysis $(6.0 \mathrm{~mm} \times 5.0 \mathrm{~mm} \times 3.0$ mm) (Fig. 1).

\section{Measurement of bone mineral density (BMD), bone mineral content (BMC) and trabecular structure}

Digital images were converted to 16-bit gray-scale TIFF format using the Atlas TIFF Convertor ${ }^{\circledR}$ (Rigaku Co., Tokyo, Japan), then analysed using TRI/3D-Bon BMD (TRI/3D-Bon; Ratoc System Engineering Co., Tokyo, Japan). For BMD, BMC and trabecular structure measurement, a hydroxyapatite calibration curve was prepared from the phantom images (hydroxyapatite content: $200 \mathrm{mg} / \mathrm{cm}^{3}, 300 \mathrm{mg} / \mathrm{cm}^{3}, 400 \mathrm{mg} / \mathrm{cm}^{3}, 500 \mathrm{mg} / \mathrm{cm}^{3}, 600$ $\mathrm{mg} / \mathrm{cm}^{3}, 700 \mathrm{mg} / \mathrm{cm}^{3}, 800 \mathrm{mg} / \mathrm{cm}^{3}$, and $1550 \mathrm{mg} / \mathrm{cm}^{3}$ ); then, BMD, $\mathrm{BMC}$ and trabecular structure of the femur were calculated using the TRI/3D-Bon trabecular structure analysis routine (autodetection mode) using the obtained CT values.

Trabecular structure measurement: The three-dimensional structure of the trabecular bone obtained by micro-CT imaging was calculated with structure model index (SMI). In this threedimensional structural analysis, trabecular thickness (Tb.Th), trabecular number (Tb.N), trabecular separation (Tb.Sp), trabecular spacing (Tb.Spac), and Trabecular Bone Pattern factor (TBPf) were determined.

\section{D-map analysis}

Bone situation (inferred from BMD values) was determined from a 3D-map showing BMD distributions, obtained by micro$\mathrm{CT}$, with the following colour coding: high BMD: red to orange; intermediate BMD: yellow to green; low BMD: light blue to purple as shown in Fig. 2. The analysis of the 3D image was conducted using TRI/3D (TRI/3D-BON; Ratoc System Engineering, Tokyo Japan) image analysis software from bone density values. 3Dmap conditions were: 1 pixel, $30 \mu \mathrm{m}$; range, $300-1500 \mathrm{mg} / \mathrm{cm}^{3}$.

\section{Microscopic examination of the non-decalcified ground section}

After immersing the femur in alcohol, fat was removed using fixation, dehydration, and xylene with methyl methacrylate resin. Resin embedding (Osteo Resin ${ }^{\mathrm{TM}}$ Embedding kit, Wako Pure Chemical Industries Co., Japan) was performed to reduce the thighbone to a single unit.

The embedded bones were cut in sagittal sections along their major axis using an automatic exact cutting machine (ISOMET, Buehler, USA) to produce non-decalcified ground sections of 100 

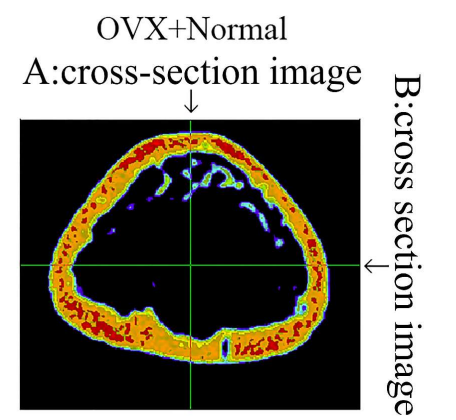

\begin{abstract}
sagital section image of $\mathrm{A}$
\end{abstract}
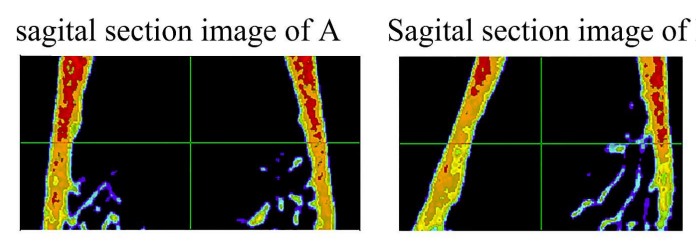

Figure 2. 3D-map analysis

BMD values were colour coded in the range of $300 \mathrm{mg} / \mathrm{cm}^{3}-1500 \mathrm{mg} / \mathrm{cm}^{3}$.
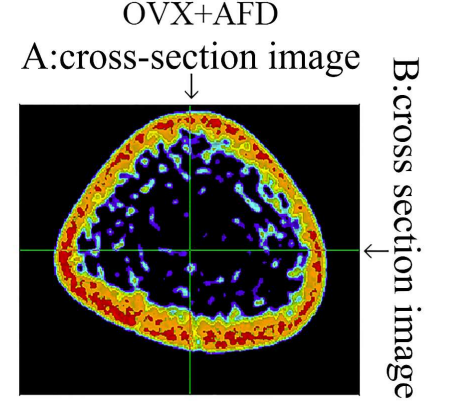

$\underline{1000 \mu \mathrm{m}}$

sagital section image of A sagital section image of $\mathrm{B}$
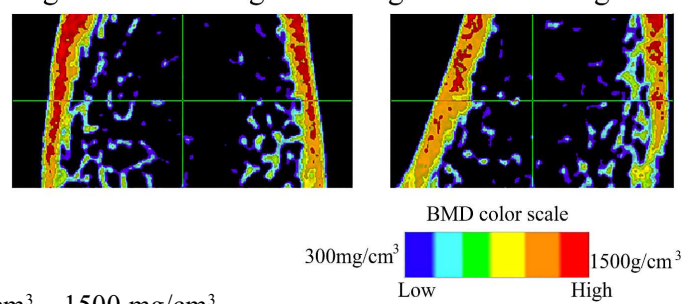

Blue to light blue represent low BMD, yellow-green to yellow intermediate BMD, and orange to red high BMD.
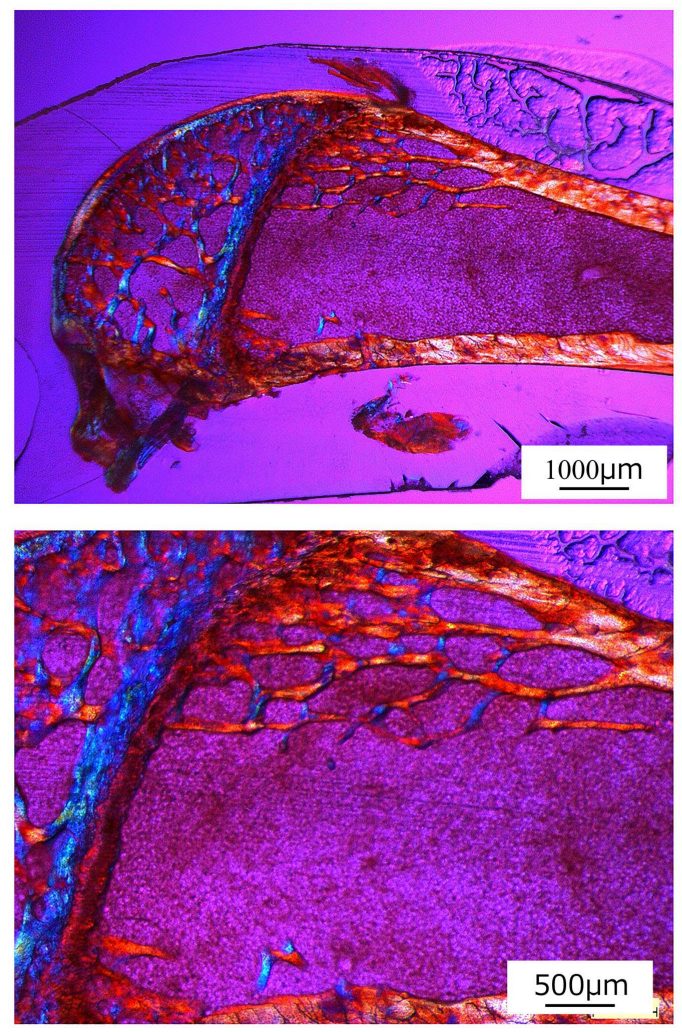

OVX+Normal
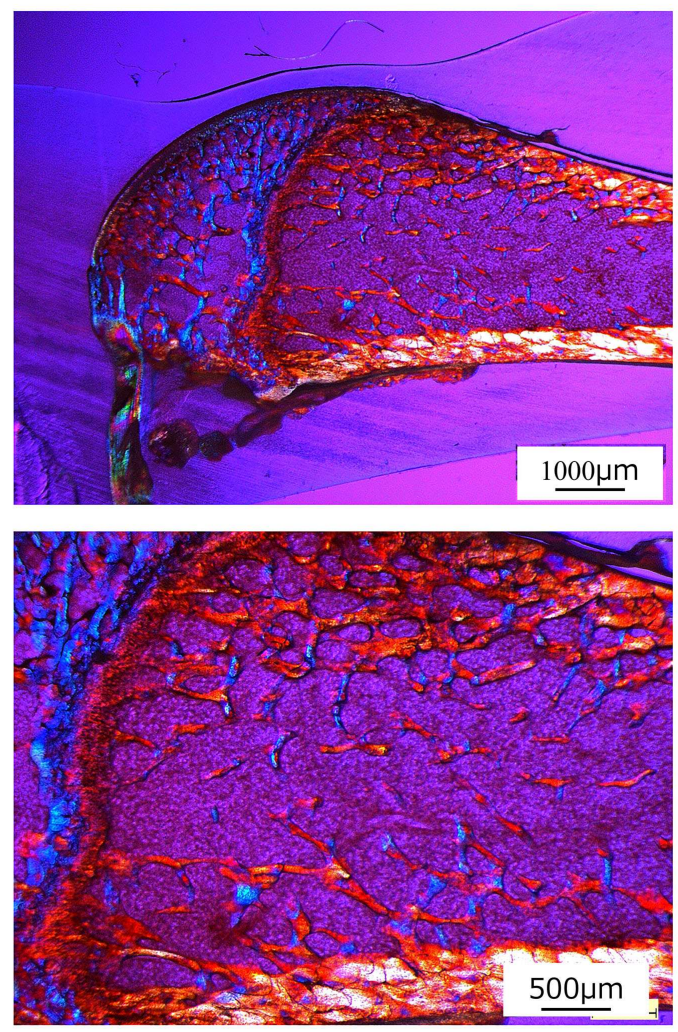

$\mathrm{OVX}+\mathrm{AFD}$

Figure 3. Polarized light micrograms (Cross Nicol method)

ìm thickness.

The cut sections were examined using a polarized-light microscope (LEICA M60, Leica Microsystems GmbH, Germany) in Cross Nicol.

\section{Statistical analysis}

Variables were presented as mean \pm standard deviation. Student's t-test was used to compare body weight, BMD, BMC, and trabecular structure between both groups, with the null hypothesis of no difference between $\mathrm{N}$ and A groups. P values < 
Kanami Sato et al.: Bone Quality Changes in Osteoporotic Rats

Table 4. Trabecular structure measurement quantifying the state of the trabecular bone in the cancellous bone.

\begin{tabular}{|c|c|c|c|c|c|c|}
\hline & $\begin{array}{l}\text { Tb.Th } \\
(\mu \mathrm{m})\end{array}$ & $\begin{array}{l}\text { Tb.N } \\
(1 / \mathrm{mm})\end{array}$ & $\begin{array}{l}\text { Tb.Sp } \\
(\mu \mathrm{m})\end{array}$ & $\begin{array}{l}\text { Tb.Spac } \\
(\mu \mathrm{m})\end{array}$ & $\begin{array}{l}\text { TBPf } \\
(1 / \mathrm{mm})\end{array}$ & SMI \\
\hline $\begin{array}{l}\text { OVX+Normal } \\
\text { OVX+AFD }\end{array}$ & $\left.\begin{array}{l}69.4 \pm 4.0 \\
76.5 \pm 2.0\end{array}\right] *$ & $\left.\begin{array}{l}0.1 \pm 0.04 \\
0.3 \pm 0.02\end{array}\right] *$ & $\left.\begin{array}{l}427.1 \pm 48.3 \\
220.8 \pm 23.3\end{array}\right] *$ & $\left.\begin{array}{l}496.6 \pm 50.5 \\
285.8 \pm 29.3\end{array}\right] *$ & $\begin{array}{l}25.7 \pm 4.9 \\
21.5 \pm 0.8\end{array}$ & $\left.\begin{array}{l}3.1 \pm 0.05 \\
3.0 \pm 0.05\end{array}\right] *$ \\
\hline
\end{tabular}

0.05 were considered statistically significant.

\section{Results}

\section{Measurement of body weight}

Table 2 shows body weight measurements for the 2 groups at each observation time. From 8 to 24 weeks after the intervention, the increase in body weight was more in $\mathrm{A}$ than in $\mathrm{N}$ groups.

\section{Micro-CT}

\section{BMD measurement}

BMD was significantly higher in A than in $\mathrm{N}$ group at 24 weeks. BMD values for the 2 groups at 24 weeks were as follows: $\mathrm{N}$ : $735.2 \pm 7.5 \mathrm{mg} / \mathrm{cm}^{3}$ and A: $768.1 \pm 11.2 \mathrm{mg} / \mathrm{cm}^{3}$ (Table 3) (BMD $\mathrm{p}<0.001)$.

\section{BMC measurement}

BMC was significantly higher in A than in $\mathrm{N}$ group at 24weeks. $\mathrm{BMC}$ values for the 2 groups at 24 weeks were as follows: $\mathrm{N}$ : $0.17 \pm 0.07 \mathrm{mg} / \mathrm{cm}^{3}$ and A: $0.67 \pm 0.13 \mathrm{mg} / \mathrm{cm}^{3}$ (Table 3) (BMC $\mathrm{p}<0.001)$.

\section{Measurement of trabecular structure}

Trabecular structure values for the 2 groups at 24 weeks were as follows: $\mathrm{N}$ : Tb.Th $69.4 \pm 4.0 \mu \mathrm{m}$, Tb.N $0.1 \pm 0.041 / \mathrm{mm}$, Tb.Sp $427.1 \pm 48.3 \mu \mathrm{m}$, Tb.Spac $496.6 \pm 50.5 \mu \mathrm{m}$, TBPF $25.7 \pm 4.91 /$ mm, and SMI $3.1 \pm 0.05$; A: Tb.Th $76.5 \pm 2.0 \mu \mathrm{m}$, Tb.N $0.3 \pm$ $0.021 / \mathrm{mm}$, Tb.Sp $220.8 \pm 23.3 \mu \mathrm{m}$, Tb.Spac $285.8 \pm 29.3 \mu \mathrm{m}$, TBPF $21.5 \pm 0.81 / \mathrm{mm}$, and SMI $3.0 \pm 0.05$ (Table 4) (Tb.Th $\mathrm{p}<0.001$, Tb.N $p<0.001$, Tb.Sp $p<0.001$, Tb.Spac $\mathrm{p}<0.001$, SMI $\mathrm{p}<0.001)$.

\section{D-map analysis}

Figure 3 shows the 3D-map for the 2 groups after 24 weeks of the intervention. Red to orange, yellow to green, and light blue to purple in the 3D-map indicate high, intermediate, and low BMD, respectively.

Most of the cortical bone section from $\mathrm{N}$ rats was shown in orange to yellow, denoting high to intermediate BMD, with occasional red areas reflecting a high BMD. The inside part of the cortical bone section from A rats appeared orange to yellow, with more red areas than in sections from $\mathrm{N}$ group. In group $\mathrm{N}$, there was little observable cancellous bone (Fig.2).

\section{Microscopic examination of the non-decalcified ground sections}

Polarized light micrograms are shown in Fig.3. Sections from A group showed stronger orange polarized light in the bone as compared to sections from $\mathrm{N}$ group.

\section{Discussion}

The purpose of this study was to examine the benefits of administering AFD to ovariectomized rats, and to assess the improvements in bone structure due to FOS, ISO, and calcium citrate contained in AFD.

The weight of rats in both $\mathrm{N}$ and A groups exhibited an upward trend at 1 week of age, and there was no difference in weight gain between both groups. Therefore, there was no difference in meal intake stemming from differences in the feed. BMD and BMC measurements of trabecular bone revealed significantly higher values for A than for $\mathrm{N}$ group. Most of the cortical bone part of the $\mathrm{N}$ group was shown with orange. Cancellous bone shown with blue $\sim$ light blue was observed near cortical bone in the medullary cavity. In A group, high BMD (shown in red) was observed in the major part of cortical bone, and intermediate to low BMD (shown in blue to green) was observed in parts of the marrow cavity. Numerical comparison of BMD revealed an approximate difference of 30 $\mathrm{mg} / \mathrm{cm}^{3}$, but visual inspection of the 3D-map revealed a difference in the trabeculae number of trabecular bone by a measurable range. Furthermore, the following parameters were used for quantification of trabecular microarchitecture: trabecular thickness (Tb.Th $(\mu \mathrm{m})$ ), trabecular number (Tb.N (1/mm)), trabecular separation (Tb.Sp $(\mu \mathrm{m}))$, trabecular spacing (Tb.Sp $(\mu \mathrm{m}))$, Structure Model Index (SMI; used to assess whether trabecular structure has plate-like or rod-like geometry), trabecular bone pattern factor (TBPF; used to assess convex, concave, and honeycomb-like trabecular surfaces). In comparing A to $\mathrm{N}$ groups to quantify and inspect the state of the trabeculae, it shows that the trabeculae are larger in size, the space between the trabeculae is smaller, and there is a larger number of trabeculae in A group. These findings suggest that the components present in AFD increased the number and promoted the growth of trabeculae. However, the connection between trabeculae did not change, as it was apparent from the values of SMI and TBPF. This difference between both groups may indicate that the 3 components of AFD improved bone turnover and were beneficial for bone formation. In A group, the thighbone metaphyseal cancellous bone showed dense trabeculae 
as compared to $\mathrm{N}$ group, based on results of the bone quantity structure measurement as observed by polarized light microscopy. Detecting orange polarized light suggested the presence of collagen fibres. Ovariectomy in an animal model mimics many types of bone loss caused by oestrogen deficiency, known to cause trabecular bone loss, which is the same cause of postmenopausal osteoporosis. ISO present in AFD has a structural resemblance to oestrogen, possess an oestrogen-like action and exhibits an affinity to oestrogen receptors such as $\mathrm{ER}^{11)}$. A component that has affinity for these oestrogen receptors, ISO daidzein is converted to equol ${ }^{12}$. It is converted into black-bellied plover and equol by ISO, and these ingredients have affinity to an oestrogen receptor ${ }^{11)}$, which inhibits bone $\operatorname{loss}^{13)}$. Furthermore, the fructo-oligosaccharides in AFD are non-digestible oligosaccharides known to enhance mineral absorption ${ }^{14)}$. Previously published reports suggest that calcium citrate, another component of AFD, is more easily absorbed than calcium carbonate ${ }^{15,16)}$.

Although calcium citrate is insoluble in water, chelation of calcium helps the calcium be absorbed by the body. Previous experiments suggest that $\mathrm{Ca}$ citrate inhibits BMD decline by suppressing elevated parathyroid hormone level in blood and thus blocking bone calcium outflow ${ }^{17}$. The aforementioned findings suggest that the components of AFD exhibit inhibitory action on bone resorption and promote bone formation stemming from improved bone turnover.

Conoscopic imaging showed that A group exhibited stronger amber coloured polarization properties in cortical bone as compared to $\mathrm{N}$ group. Although a big difference in birefringence between both groups was not observed, A group exhibited denser trabecular bone than $\mathrm{N}$ group. These differences between both groups may be the result of active bone remodelling facilitated by components of AFD. Thus, the bones of the ovariectomized rats may have improved due to the action of AFD.

These findings suggest that AFD is effective for treating osteoporosis through its ability to increase the rate of bone turnover following calcium absorption in the body. This experiment took in AFD for long-term (24 weeks), and, as a result, improvement of the bone substance was found. Therefore, we thought that it was necessary to examine an optimal intake period on taking in AFD.

Also, we examined the metabolic pathway of AFD and thought that confirmation of the harm was important.

AFD may improve bone turnover in osteoporosis and expected to prevent the incidence of falls and bone fractures, and thus could be valuable for improving and maintaining the QOL of the elderly.

\section{Conflict of Interest}

The authors have declared that no COI exists.

\section{References}

1. Cabinet office, Government of Japan. http://www8.cao.go.jp/ kourei/english/annualreport/2015/pdf/c1-1.pdf

2. Verschueren S, Gielen E, O’Neill TW, Pye SR, Adams JE, Ward KA, Wu FC, Szulc P, Laurent M, Claessens F, Vanderschueren D and Boonen S. Sarcopenia and Its Relationship with Bone Mineral Density in Middle-aged and Elderly European men. Osteoporos 24: 87-98, 2013

3. Itamar L, Steven P and Gustavo D. Sarcopenia and Osteoporotic Fractures. Clinic Rev Bone Miner Metab 14: 38-44, 2016

4. Kuzuya M, Fukatsu K, Raynaud-Simon A, Christian Sieber C, Bauer JM and Schneider SM. Topic 36 Nutrition in the Elderly. Joumyaku Keicho Eiyo 26: 935-954, 2011

5. Grant AM, Avenell A, Campbell MK, McDonald AM, MacLennan GS, McPherson GC, Anderson FH, Cooper C, Francis RM, Donaldson C, Gillespie WJ, Robinson CM, Torgerson DJ and Wallace WA. Record trial group. Oral vitamin D3 and calcium for secondary prevention of lowtrauma fractures in elderly people (Randomised evaluation of calcium or vitamin D, record): A randomised placebocontrolled trial. Lancet 365: 1621-1628, 2005

6. Porthouse J, Cockayne S, King C, Saxon L, Steele E, Aspray T, Baverstock M, Birks Y, Dumville J, Francis R, Iglesias C, Puffer S, Sutcliffe A, Watt I and Torgerson DJ. Randomised eontrolled trial of calcium and supplementation with cholecalciferol (vitamin D3) for prevention of fractures in primary care. BMJ 330: 1003, 2005

7. Lima GA, Lima PD, Barros Mda G, Vardiero LP, Melo EF, Paranhos-Neto Fde P, Madeira M and Farias ML. Calcium intake: Good for the bones but bad for the heart? An analysis of clinical studies. Arch Endocrinol Metab 60: 252-263, 2016

8. Nakada H, Sakae T, Watanabe T, Takahashi T, Fujita K, Tanimoto Y, Okada H, Kaneda K, Kato T and Kawai Y. A new osteoporosis prevention supplements-diet improve bone mineral density in ovariectomized rats on micro-CT. J Hard Tissue Biol 23: 1-8, 2014

9. Nakada H, Sakae T, Watanabe T, Takahashi T, Fujita K, Tanimoto Y, Okada H, Kaneda K, Kato T and Kawai Y. Structure model index changes in the femoral epiphyseal region on micro-computed tomography caused by a supplement diet in ovariectomized rats. J Hard Tissue Biol 23: 169-176, 2014

10. Sato K, Takahashi T, Nakada H, Sakae T, Watanabe T, Sato H, Gunji A, Tanimoto Y and Kawai Y. The effect of combined fructo-oligosaccharides, isoflavone, and citric acid calcium on the bone quality of thighbone metaphysis in osteoporotic rats. J Hard Tissue Biol 26: 43-50, 2017

11. Ishimi Y, Arai N, Wang X, Wu J, Umegaki K, Miyaura C, Takeda A and Ikegami S. Difference in effective dosage of 
Kanami Sato et al.: Bone Quality Changes in Osteoporotic Rats

genistein on bone and uterus in ovariectomized mice. Biochem Biophys Res Commun 11: 697-701, 2000

12. Fujioka M, Uehara M, Wu J, Adlercreutz H, Suzuki K, Kanazawa K, Takeda K, Yamada K and Ishimi Y. Equol, A metabolite of daidzein, inhibits bone loss in ovariectomized mice. J Nutr 134: 2623-2627, 2004

13. Wu J, Wang X, Chiba H, Higuchi M, Nakatani T, Ezaki O, Cui H, Yamada $\mathrm{K}$ and Ishimi Y. Combined intervention of soy isoflavone and moderate exercise prevents body fat elevation and bone loss in ovariectomized mice. Metabolism 53: 942-948, 2004

14. Sakuma K. Molecular mechanism of the effect of fructooligosaccharides on calcium absorption. Biosci Microfl 21: 13-20, 2002

15. Nicar MJ and Pak CYCm. Calcium bioavailability from calcium carbonate and calcium citrate. J Clin Endocrinol Metab 61: 391-393, 1985

16. Harvey JA, Zobitz MM and Pak CY. Dose dependency of calcium absorption, a comparison of calcium carbonate and calcium citrate. J Bone Miner Res 3: 253-258, 1988

17. Heller HJ, Greer LG, Haynes SD, Poindexter JR and Pak CYC. Pharmacokinetic and pharmacodynamics comparison of two calcium supplements in postmenopausal women. J Clin Pharmacol 40: 1237-1244, 2000 
J.Hard Tissue Biology Vol. 26(2): 215-222, 2017 